This item was submitted to Loughborough's Research Repository by the author.

Items in Figshare are protected by copyright, with all rights reserved, unless otherwise indicated.

\title{
Psychology, sociology and interaction: disciplinary allegiance or analytic quality? - a response to Housley and Fitzgerald
}

\section{PLEASE CITE THE PUBLISHED VERSION}

http://dx.doi.org/10.1177/1468794108095078

\section{PUBLISHER}

(c) Sage

VERSION

AM (Accepted Manuscript)

\section{LICENCE}

CC BY-NC-ND 4.0

\section{REPOSITORY RECORD}

Edwards, Derek, Alexa Hepburn, and Jonathan Potter. 2019. "Psychology, Sociology and Interaction: Disciplinary Allegiance or Analytic Quality? - a Response to Housley and Fitzgerald". figshare. https://hdl.handle.net/2134/15016. 
This item was submitted to Loughborough's Institutional Repository (https://dspace.lboro.ac.uk/) by the author and is made available under the following Creative Commons Licence conditions.

\section{creative
commons}

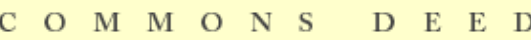

Attribution-NonCommercial-NoDerivs 2.5

You are free:

- to copy, distribute, display, and perform the work

Under the following conditions:

Attribution. You must attribute the work in the manner specified b the author or licensor.

Noncommercial. You may not use this work for commercial purposes.

No Derivative Works. You may not alter, transform, or build upon this work.

- For any reuse or distribution, you must make clear to others the license terms of this work.

- Any of these conditions can be waived if you get permission from the copyright holder.

Your fair use and other rights are in no way affected by the above.

This is a human-readable summary of the Leqal Code (the full license).

\section{Disclaimer 만}

For the full text of this licence, please go to: http://creativecommons.org/licenses/by-nc-nd/2.5/ 
PSYCHOLOGY, SOCIOLOGY AND INTERACTION: DISCIPLINARY ALLEGIANCE

OR ANALYTIC QUALITY

Derek Edwards, Alexa Hepburn and Jonathan Potter

Discourse and Rhetoric Group

Department of Social Sciences

Loughborough University

Loughborough

Leicestershire, LE11 3TU
Email: D.Edwards@lboro.ac.uk

Email: A.Hepburn@lboro.ac.uk

Email: J.A.Potter@lboro.ac.uk

Publsihed as:

Edwards, D., Hepburn, A. \& Potter, J. (2009). Psychology, sociology and interaction: Disciplinary allegiance or analytic quality?, Qualitative Research, 9, 119-128. 


\section{A DISCURSIVE APPROACH TO PSYCHOLOGICAL MATTERS}

One of the features of various academic responses to discursive psychological research has been a mistaken representation of the status of the 'psychological'. Sometimes the assumption is made that it involves the attempt to make a psychology-based intervention in social science debates. The recent HF paper to which we are responding provides another example of this confusion. In this paper we take the opportunity to tackle some of these confusions head-on, beginning with a consideration of some of discursive psychology's (hereafter DP) antecedents.

In the early 1960s, when Sacks was starting to develop the ideas that were later to become foundational for conversational analysis, psychology did not figure highly in his interests (Sacks, 1992). His theoretical and analytic foils tended to be Parsonian sociology or Chicago school ethnography, and his critique of both was built up through the course of the lectures. Despite his lack of specific focus on psychology, Sacks' work can now be understood to provide a radical alternative to traditional cognitivist approaches to psychology (Edwards, 1995). Most fundamentally, he rejected the prevailing John Locke style picture of language as a set of signs for transporting thoughts from one mind to another, in favour of considering talk as a medium for action. His focus was on the basic issue of how language can work as something that can be both learnable and understandable. Very early on (in the Spring of 1964) this led to his often quoted caution about researchers using cognitive intuitions:

When people start to analyze social phenomena, if it looks like things occur with the sort of immediacy we find in some of these exchanges, then, if you have to make an elaborate analysis of it - that is to say, show that they did something as involved as 
some of the things I have proposed - then you figure that they couldn't have thought that fast. I want to suggest that you have to forget that completely. Don't worry about how fast they're thinking. First of all, don't worry about whether they're 'thinking.' Just try to come to terms with how it is that the thing comes off. Because you'll find that they can do these things (Sacks, 1992, vol. I: 11).

On the whole, conversation analysis has followed this injunction, which has appropriately disengaged it from cognitivist thinking. Instead the focus has been very much on what is seeable or hearable in interaction. Sacks started with the issue of how conversation makes sense (in all its rich detail of intonation, stress, timing and so on) and how issues such as understanding, knowledge, and evaluation are delivered conversationally. From this point of view cognition - mind, thoughts, intentions and so on are relevant to, and involved in, interaction in terms of their current hearability in the interaction itself. This is quite distinct from the classic psychological project of discovering the nature of peoples' mental furniture, and also different from the critical social psychological project of exploring peoples' ideologically built interiority. Sacks quoted approvingly Freud's observation that 'the problem is not how is it that people come to think that others know their thoughts, but how is it that people come to think so deeply that others don't know their thoughts?' (Sacks, 1992, vol. I: 114).

One way of understanding the intellectual place of discursive psychology (henceforth DP) is of taking the kinds of fragmentary focus on psychological matters we see in Sacks' work and developing their implications more systematically. This has involved considering psychological concerns as features of situated practices; and that, in turn, is part of a radical and wholesale respecification of the project of psychology. Part of the development of DP has involved a now longstanding dialogue with cognitivist and social cognitivist psychology 
(e.g. Edwards \& Potter, 1992). Typically this has involved an exploration of the implications that understanding peoples' talk as dialogically, sequentially and practically organized has for the empirical basis of cognitive research studies. One of the features that distinguished most DP from even closely related traditions of discourse analysis was its use of records of natural interaction. This meant that DP worked with psychology situated in specific everyday or institutional settings - police interrogations, psychiatric assessments, and family mealtimes. This is in sharp contrast with mainstream social cognitive tradition in psychology, which overwhelmingly models action ('behaviour') experimentally with the aim of adducing general, trans-situation, trans-historical processes.

Another part of this development has involved a more systematic and cumulative set of studies of the way psychological matters such as intention, assessment, upset, understanding become live as participants' concerns (see examples in Potter, 2007) and the way the 'subjective' and 'objective' sides are built and invoked in, for example, activities such as complaining (Edwards, 2007) ${ }^{1}$. There has also been an interest in the use of what conceptual analysts would call psychological predicates such as 'honesty' (Ed \& Fass) and 'concern' (Pott \& Hep) as well as a growing body of work on the situated procedures through which psychological entities are methodically constitutes as the objects of social science (e.g. Antaki). For recent reviews of DP see, for example, Edwards [fitch] and Hepburn \& Wiggins (2007).

\section{DISCURSIVE PSYCHOLOGY AND THEORETICAL AMNESIA}

Housley \& Fitzgerald's (200*) article (henceforth HF) claims that DP suffers from 'theoretical amnesia' with respect to the analysis of accounts and motives. It claims to 
confront that amnesia by reemphasising the 'sociological canon of interactionism, phenomenology and ethnomethodology/CA' (ms. 5) and by demonstrating the way in which 'accounts' and invocations of 'inner' states must be understood in terms of the practical accomplishment of social organization. HF offers some critical observations about a paper by Edwards (2006) that are taken to show a relatively covert 'importing a psychological intention' and is taken to reveal contradictions between theory and analytic practice and it goes on to offer some indicative analyses of its own working with different kinds of material.

There are many things of value in HF. However, we are doubtful of its approach to disciplines and the importance of 'canon'; we find a range of confusions and problems in its representation of DP; and we find important limitations in the offered analytic alternatives. We will take these areas in turn.

\section{Disciplines and the canon}

There are many ways of constructing the history of Sociology as a discipline and judging the crucial 'canon' of interactional work. Although the Catholic Church has the Pope to pronounce which books should be sacred (OED's core meaning of 'canon'), things are more open in the social sciences. We are less concerned about Sociology (or Psychology, or Linguistics, even) as disciplines than with generating progressive theorizing and developing powerful analytic work. HF's promotion of a canon seems to us to be a conservative move. Moreover, HF's claim about amnesia is simply erroneous and their specific identification of the canon at the very least problematic.

The claim about amnesia does not stand serious scrutiny. Let us just indicate coverage in some key works. The tradition of accounts and motives that includes Mills and Scott and Lyman is discussed in detail, for example, in Potter \& Wetherell (1987) where 
important elements of discursive psychology were being developed. That book also discusses ethnomethodology both in general terms and in a wide range of specific examples, including Coulter's work; it also draws on conversation analysis in virtually every chapter, showing the early appreciation of how central conversation analysis would be to the analysis of psychological matters. Edwards \& Potter (1992) can be read as a thoroughgoing exploration of the idea that motives and accounts are social objects, moving the discussion forward by taking an ethnomethologically inspired consideration of the active role of description. Again conversation analytic work is central as providing a way of understanding what 'situated action' actually involves analytically. Edwards (1997) and Potter (1996) are both characterised by deep engagements with ethnomethodology and conversation analysis. There are undoubtedly arguments to be had on the interpretation of this work (as evidenced by Coulter, 1979; Potter \& Edwards, 200*, for example) but there is no amnesia.

One of the problems with $\mathrm{HF}$ is that it is organized around disciplinary allegiance and sacred texts rather than around the specific arguments and analytic developments. For example, the traditions collected as the canon (interactionism, ethnomethodology and conversation analysis) are both radically at odds and characterised by important theoretically nuanced disputes. The separation between symbolic interactionism and ethnomethodology and conversation analysis has been clear since at least the early 1970s (Douglas??, Turner?? Ref?). However, there are now key distinctions to be made between the early ethnomethodology and the more recent studies of work programme (Garfinkel, 1967; 2002). Likewise there are different emerging foci in conversation analysis, partly in consideration to how foundational sequential analysis will be and how far turn design can be analysed in an autonomous manner, and partly in consideration of how far conversation 
analysis can be merged with work that uses standard sociological variables. Blurring over these important differences in pursuit of a canon is a recipe for confusion rather than constructive theory development. $^{2}$

\section{HF's critique of Edwards}

HF discuss Edwards (2006) with the aim of showing inconsistencies in the use of cognitive notions and of promoting a slippage between analysis and evidence. The article claims that mentalistic notions are introduced into the analysis when they are not documented in relevant parts of the materials. [we need to set out the bare bones of DE's original paper, and a bit more of a summary of their criticism of $D E$, for this defense to make sense (esp as we're not appearing in same issue)] Before we address this criticism, let us stand back and make some important points. First, even if there were inconsistency in this one article, that would not in itself be evidence that it is either widespread or that the contradiction is theoretically revealing. There is now a large body of discursive psychological studies (see Hepburn and Wiggins, 2005, 2007 for reviews, summaries and illustrations of recent DP studies) and we do not expect them to be uniformly flawless. Second, Edwards (2006) is an inapposite choice because it is an illustrative piece arguing a case rather than a fully documented analytic study (in fact, the relevant full studies using the material in case are published as Edwards, 200*, 200*). Third, given that there are plenty of general statements in discursive psychological methodological writing that emphasise the importance of working with participants' orientations (e.g. Potter, 2003) what would a single practical deviation show about the program as a whole?

There are two important points to be made, however, with respect to HF's specific critical claim. First, Edwards (2006) does not claim anything about the police officer having 
an "intention or motive" to say what he said, nor that he subsequently formulated any such intention or motive - that claim, imputed to Edwards, is entirely H\&F's. Instead the paper refers to the officer's "appreciation" of the notion of recklessness in Law, evidenced elsewhere, and Edwards makes that understanding relevant to his current line of inquiry. This is not, then, offering a psychological, motivational, intentional theory of talk. Second, the quoted example was, as indicated at the time, a shorthand, somewhat ethnographic gloss used for the purposes of highlighting the broader significance-for-police-work (now explored more fully in Edwards, 200*). The main thrust of the example was, the way intent to perform actions is descriptively separable from intentions to cause their consequences, which is indeed an important feature of talk and action in legal settings. The illustration was not at all offered as expressing the police officer's own intentions and motives in speaking nor as endorsing these things as coherent or appropriate topics for DP study.

It is generally the case that contextually relevant matters, though analysable in their own right, may usefully be glossed when analysing specific actions. That is what happens when, for example, Schegloff (ref**) informs us, contextually to some data and its analysis, that these are an estranged husband and wife talking about their son; or when analysing Oliver North's testimony, Bogen and Lynch (ref**) tell us who North is, gloss the political context, and the general nature of the interrogation from which examples are provided for analysis. Such helpful information is not designed to obscure the fact that the status, say, of Joey as the son of Marsha and Tony is not analysable for precisely how, when, and for what, it is formulated or made specifically relevant. Indeed, H\&F themselves provide just such helpful glosses (with which we have no problems at all) when informing us, contextually to a data extract, that the 'Phillips report had suggested that individual blame was not 
appropriate in the case of the BSE crisis; whilst a culture of secrecy had provided a source of problems in dealing with the crisis at an organisational level' (HF, ms. 22).

\section{Housley and Fitzgerald's analytic examples}

We have no particular interest in attacking HF's analytic examples. They are, after all, all interesting and worthy of systematic study. We feel obliged to make some observations, however, as they are offered as improvements on what currently exist in DP. HF analyse the following example from a radio phone in:

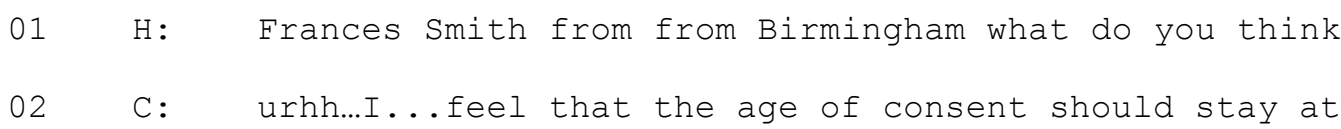

They claim that while 'asking what someone 'thinks' is a routine interactional method for eliciting an opinion in interaction, here it is demonstrably part of the institutional and sequential organisation of the program... it is an interactional method for introducing the next caller on air through placing the caller in the next turn position to answer (HF, ms. 19). This is very limited analysis; for example it ignores the obvious identifying address form 'Frances Smith from Birmingham' that precedes it. This leaves HF in the odd position of claiming 'what do you think' is the host's 'method for introducing the next caller'.

HF's point is, no doubt, that 'think' can be analysed in a way that does not treat it as a mental object. As researchers not afflicted by sociological amnesia, we are familiar with similar analyses from ethnomethodologists (cf. Coulter, 1979) and have developed analyses of 'think' in practice which are non-cognitivist (Edwards \& Potter, 2005; Potter, 2007; more??*). It is therefore not clear in what sense this entails any improvement on our own work. 
HF offer the following observation: 'clearly we cannot know if this is the real opinion of the caller, what the caller really thinks about this topic' (HF, ms. 19). This suggests that they themselves are working with a distinction between the talk and what lies underneath it: the real opinion of the caller. In DP we should emphasise, the notion that a member might be expressing a real or genuine thought or opinion is also a member's practical concern, not an invisible entity lying behind the talk. H\&F also gloss the caller's talk as expressions of an 'opinion'. Yet why this word? Why not rather describe them as 'judgements', or 'conclusions', or even 'knowledge claims'? Those are very different kinds of epistemic categories, implying different kinds of grounding and commitment. In fact, the host and caller provide for the caller's claim about 'left wing' prison officers as grounded in experience. So, is an experientially grounded claim to know something, an 'opinion'? Let us emphasise again, that we are not suggesting that HF's analyses are uninteresting or without merit - however, insofar as they are offered as illustrating a more coherent approach to 'psychological matters' we think they are seriously mistaken.

Let us restrict ourselves to a few more comments about HF's second extract and its analysis. As part of developing their criticisms H\&F note the importance of sequence organisation, repair and preference organisation for their own understanding of accounts (HF, ms. 11). It is therefore odd that none of these analytic resources appear in this paper. For example, extract 2 contains a number of self- and other-initiated repairs, the latter in particular being crucial in unpacking the activities performed by the interviewer's questions. They focus in particular on the following fragment from extract 2 , in which the caller offers a description of uniformed prison officers:

12 Caller: I think that these um a strong left wing element in the uniformed service 
13 Host: Left wing element?

14 Caller: Yes

Rather than glossing the interviewer's turn ('left wing element') on 13 as an other-initiated repair providing a candidate understanding of, and so displaying some trouble with, the prior turn, H\&F opt for simply noting that 'a clarification is sought' (HF, ms. 21) and that this action invokes 'a possible category disjuncture between a social category and the opinions and motives predicated to that category' (HF, ms. 21). They note that in doing this the interviewer 'displays an alternative opinion' (HF, ms. 21) to the one displayed by the caller i.e. that uniformed prison officers are not left wing. However, the sense of the interviewer's turn being oppositional is brought about by its very sequential position and nature as an other-initiated repair operating through a repeat of the prior (ref Schegloff***). Surely this kind of structural and sequential point is crucial to H\&F's argument that opinions and accounts are dependent on the 'the situated action and context of their production' (HF, ms. 24)? However, repeats of the prior, and the repair work that they can elicit, display trouble with the prior turn. In this institutional environment such trouble may be designed to elicit clarification for the overhearing audience. In what sense do we need to import a putative 'opinion' of the Host?

Moreover, H\&F's whole argument here is designed to show that 'opinions' are best analysed in terms of how they are displayed interactionally, but this is a foundational discursive psychological point (Potter, 1998), which has been made more explicitly and clearly in a number of publications (Puchta and Potter etc) so it's not clear who the target of H\&F's argument ought to be.

The oppositional sense of line 13 in extract 2 is also displayed by its contrastive stress, and yet this is not noted by H\&F, who elsewhere in their critique of Edwards (2006) 
make much of the importance of having a detailed transcript for warranting analytic claims made (HF, ms. 17). It is therefore disappointing that their transcripts are missing a number of key features - the timing of pauses and gaps, key points of emphasis, delivery and pitch change, and closing and continuing intonation, all of which are crucial for understanding the actions and projects underway (we requested access to soundfiles but they were unavailable). Line 13 is one of the few times that the reader is given any sense of how the turn was delivered, and there remains uncertainty as to whether this represents emphasis (in line with Jeffersonian CA conventions; Jefferson, 2004) or a pitch change (suggested by their own index).

We could go on, but we hope that we have made the point sufficiently. Discursive psychology is neither cognitivist nor anti-sociological. It certainly raises questions with HF's illustrious canon, but is happy to do so. It continues to be defined by systematic and careful studies which consider psychological matters in terms of their place in situated practices. It continues to develop through close engagement with conversation analysis and new empirical materials.

\section{References}

Coulter, J. (1999). Discourse and mind, Human Studies, 22: 163-181.

Edwards, D. (2005). Moaning, whinging and laughing: The subjective side of complaints. Discourse Studies, 7, 5-29.

Edwards, D. (2006). Facts, norms and dispositions: Practical uses of the modal would in police interrogations. Discourse Studies, 8 (4), 475-501. 
Edwards, D. (2007). Managing subjectivity in talk. In A. Hepburn \& S. Wiggins (Eds.),

Discursive research in practice: New approaches to psychology and interaction (pp.

31-49). Cambridge, UK: Cambridge University Press.

Edwards, D. and Potter, J. (1992). Discursive Psychology. London: Sage.

Edwards, D. \& Potter, J. (2005). Discursive psychology, mental states and descriptions. In H. te Molder \& J. Potter (Eds). Conversation and cognition (pp. 241-259). Cambridge: Cambridge University Press.

Garfinkel, H., (1967) Studies in ethnomethodology. Englewood Cliffs, N.J.: Prentice-Hall

Hepburn, A. \& Wiggins, S. (Eds.)(2005). Developments in discursive psychology, Discourse \& Society (special issue) 16(5).

Hepburn, A. \& Wiggins, S. (Eds.) (2007). Discursive research in practice: New approaches to psychology and interaction. Cambridge: Cambridge University Press.

Jefferson, G. (2004). Glossary of transcript symbols with an introduction. In Lerner, G.H. (Ed). Conversation Analysis: Studies from the first generation (pp. 152-205). Amsterdam/Philadelphia: John Benjamins.

Potter, J. (1996) Representing reality: Discourse, rhetoric and social construction. London; Sage.

Potter, J. \& Edwards, D. (2003). Rethinking cognition: On Coulter, discourse and mind, Human Studies, 26, 165-181.

Potter, J. \& Hepburn, A. (2003). I'm a bit concerned - Early actions and psychological constructions in a child protection helpline, Research on Language and Social Interaction, 36, 197-240. 
Sacks, H. (1992). Lectures on conversation. Vols. I \& II, edited by G. Jefferson. Oxford: Basil Blackwell.

Schegloff, E.A. (2007). Sequence organization in interaction: Volume 1: A primer in conversation analysis. Cambridge: Cambridge University Press.

Schegloff, E.A. (2006). A tutorial on membership categorization, Journal of Pragmatics, 39, $462-82$.

Say something about use of ethno tradition - coulter, bogen n Lynch. Recognize contribution + interesting debates (Coulter/Potter+Edwards), but also attempting something more systematic and joined up. More than demonstrations, more use of the apparatus of $\mathrm{CA}$, more move beyond conceptual analysis.

This is ignoring further complexity in what counts as discursive psychology. Harre? Wetherell? Billig? Contrast to CA or building on $\mathrm{CA}$ ? 